\title{
The Effect of Gel and Pressure Induced Flow (PIF) Processing Conditions on the Dispersion and Intercalation of MMT Nanoclay in UHMWPE/ Montmorillonite (MMT) Clay Based Nanocomposite Sheets
}

\author{
Musa E. Babiker, Zhang Sen, Tang Yi Fei, Guangcheng Wang \& Yu Muhuo (Corresponding author) \\ State Key Laboratory for Modification of Chemical Fibers \& Polymer Materials \\ College of Material Science \& Engineering, Donghua University \\ Shanghai, P.O. Box 201620, China \\ Tel: 86-139-0175-9052 E-mail: yumuhuo@dhu.edu.cn
}

\begin{abstract}
The paper analyzes the effect of gel and pressure induced flow processing on the dispersion and intercalation of MMT nanoparticles. To reach our objective, we conducted various experiments for the preparation of dispersed nanoclay in nanocomposite sheets based on the preparation of UHMWPE gel sheet with MMT through the use of paraffin oil (solvent) and then removed the solvent utilizing PIF and extraction processes. The analysis of the UHMWPE microstructure sheet by X-Ray diffraction (XRD); transmission electron microscopy (TEM); Scanning electron microscope (SEM); and differential scanning calorimetry (DSC) was done as well. Our results highlight that good dispersion, partial exfoliation and full intercalation of MMT nanoparticle effective; that intercalated nanocomposites and the different layers correspond to flexibility chains and the presence of multi-peaks are due to the processing of different materials. The images obtained by SEM present a gel-like layers structure of UHMWPE/MMT sheet is the consequence of the deformation and re-arrangement of the gel sheets during PIF process.
\end{abstract}

Keywords: UHMWPE/MMT clay nanocomposites sheet, Gel process, Pressure-induced flow, Dispersion

\section{Introduction}

Since the last two decades, there has been revolutionary progress in the field of nanocomposite and microscale materials. Clay-Polymer nanocomposites as one of these materials has recently attracted researchers and professionals, attention as they enhance mechanical and thermal properties when compared to conventional materials. Because of their properties, the nanocomposite materials present a wide range of applications depending upon the type of inorganic material that is present in the polymers. The progress of polyolefin-clay nanocomposites is an interesting field of materials that is growing rapidly. These materials have a basic role of enhancing mechanical and physical properties in comparison with the pure polymer Alexandre et al. (2000). When those materials are processed by gel and pressure induced flow processes, better properties are expected.

In the past decade, preparation of dispersed, intercalated and exfoliated MMT clay with HDPE nanocomposites have emphasized experimental studies of their morphology and mechanical properties (Tanniru et al. 2006; Min et al. 2006) to reveal that it has been reported that strengthening of HDPE with MMT clay platelets will improve the morphology and mechanical properties of HDPE compared with the pure PE. Quang et al. (2007) improved a new technique for exfoliating and dispersing nanoclay particles into polypropylene matrices using supercritical carbon dioxide. This method relies on rapid expansion of the clay followed by direct injection into the extruder where the mixture is dispersed into the polymer melt. The nanocomposites showed more effective than conventional composites in reinforcement when the montmorillonite clay modified by using the reactive intercalating agent and the PE/clay nanocomposites were then prepared by melt intercalation method. Zhao et al. (2005)

In general, the most serious factor that governs the final development in the morphology properties of polymer/MMT clay nanocomposites is the level of dispersion, exfoliation and intercalation of the nanoclay in the nanocomposite structure. Hotta et al. (2004) studied the melt compounding of many different organoclays into linear low density polyethylene and established that clay loading resulted in increase in modulus and the clay was largely exfoliated. Homminga et al. (2005) stated that the intercalation and exfoliation of the clay are largely accelerated in the presence of flow. However, a negative effect of the screw speed on exfoliation was also 
observed in the specific case of a polybutadiene/organoclay system. Sarashi et al. (2003) acknowledged that the intercalation of MMT clay with styrene and butadiene monomer before polymerization. Only partial achievement has been achieved in compounding organo-MMTs with styrene-butadiene rubber to prepare rubber nanocomposites. Knudson et al., (2002) discovered that flocculation of the aqueous blend of styrene-butadiene latex and MMT clay gives an exfoliated clay-rubber nanocomposite. The approach offers the most convenient and effective method for the preparation of clay-styrene-butadiene rubber nanocomposites. Researchers (see for instance Sadhu et al. 2004) have shown that the styrene-butadiene rubber dissolved into toluene (as a polymer solution) and organically treated and untreated MMT was dispersed into the polymer solution. The organoclays was prepared by the exchange of octadecyl amine. The toluene was removed by evaporation. The untreated clay was intercalated with polymer; the organically treated clay was fully exfoliated. The exfoliated rubber nanocomposite has significantly improved mechanical properties when compared to the intercalated rubber nanocomposite. Both rubber composites had superior mechanical performance when compared to the pure rubber. Mousa et al. (2001) observed that the same organoclays that was utilized in Sadhu et al. (2004) was compounded with styrene-butadiene. The rheology of the polymer nanocomposite highlighted shear rate thinning behavior. This is common with MMT dispersed systems. The mechanical properties were as predicted except the increase in percent elongation to failure as a function of clay loading. The percent elongation to failure increased along with modulus and tensile strength. This is not expected or predicted by standard reinforcing theories. Ganter et al. (2001) argued that the organoclay-styrene-butadiene rubber nanocomposites by dispersing the rubber and organoclay in toluene and evaporating the solvent to prepare the rubber nanocomposite. For Federica et al. (2008) they stated that the exfoliation and dispersion of the clay in polymer nanocomposites depend on several factors such as the nature of the polymer, the nature of the clay, the type, packing density, and the size of the organic modifier on the silicate layers. Yong et al. (2007) affirmed that the influence of nanoclay on properties of HDPE/Wood composites by two steps; melt compounding and then injection molding. Yang et al. (2008) acknowledged that the dispersion polymerization based on stabilization by nano-platelets is achieved without using any other conventional stabilizers.

\subsection{Pressure Induced Flow (PIF) Process}

PIF gel sheet technique is a simple method to prepare thin, flexible sheets and composite based upon pressure and removal of the solvent. The process is based on subjecting the gel sheet in a swelling state under pressure. However, the re-arrangement of the gel molecules is effective because of the removal of solvent from the gel sheet. The thin and highly tuning gel sheet can be precisely controlled to achieve optimized gel sheet properties. Gonzalez et al. (2003) highlighted different aspects of fabricating plastic materials by PIF process. When this material is placed under pressure, the rigid plastic starts to dissolve into the soft region, creating a mixture that can flow like slurry of ice and water, which enables the material to be molded into an object. When the pressure is released, the plastic re-hardens, which indicated that the pressure was enough to make a polymer designing act like a fluid. Bartczak et al. (1996; 2005) observed the advantages from the plane-strain compression in a channel die for applying such a mode of deformation is that the deformation is homogeneous in the whole range of the strain without necking or local instabilities, and avoids internal cavitations and related artifacts. Besides, the channel die plane-strain compression is kinematically identical to plane-strain tension, which results in one direction flow of the polymer in plane-strain conditions. The use of a deep channel-die is the approach to produce samples by compression in such a die is relatively large, sufficient for other experiments. After compression, the structure and orientation produced by plastic deformation in such large specimens could be investigated.

\section{Experimental}

\subsection{Materials}

The UHMWPE used in this study was supplied by Celanese (China) Holding Co. Ltd with (Mw $=5 \times 106$ kgmol-1, Mw/Mn = 8) and was used as received. Organo-MMT clay was supplied by Zhejiang Fenghong clay chemicals Co. Ltd, (China), with average lamellar thickness less than $25 \mathrm{~nm}$; mean diameter $\mathrm{nm} 25 \mathrm{X} 1000$; content montmorillonite $95-98 \%$, and density $1.8 \mathrm{~g} / \mathrm{cu} . \mathrm{cm}$. Paraffin oil (Shanghai- China), density $\left(20^{\circ} \mathrm{C}\right)$ is $0.835-0.855 \mathrm{~g} / \mathrm{ml}$, and boiling point at $340^{\circ} \mathrm{C}$. Oxidative degradation of the polyethylene was prevented by mixing all solutions with $0.5 \mathrm{wt} \%$ (weight of paraffin oil) of antioxidant 2, 6-Di-tert-butyl-p-cresol M. p $69 \sim 71^{\circ} \mathrm{C}$. And $\mathrm{N}$-hexane with density $\left(20^{\circ} \mathrm{C}\right)$ is $0.6583 \sim 0.6613 \mathrm{~g} / \mathrm{ml}$, and refractive index $1.3741 \sim 1.3761$.

\subsection{Sample Preparation}

For the gel-processing, 6 samples were prepared using the materials listed in Table 1. The recipe was dissolved in a beaker $(250 \mathrm{ml})$ with paraffin oil at $120^{\circ} \mathrm{C}$ followed by hand stir to distribute the material in the solvent and 
to prevent generation of bubbles. When the temperature reached $130-135{ }^{\circ} \mathrm{C}$, a white solution of UHMWPE gel was formed; the stirred was stopped and the solutions were stored at $150^{\circ} \mathrm{C}$ for 48 hours and subsequently cooled slowly to room temperature.

Insert Table 1 about here

\subsection{PIF experiments}

PIF was designed as a mini-mold apparatus in this study. The PIF stages were performed using the weighting as a compression tool. Four types of different size and geometry were used in this study. As shown in Fig. 1. The first apparatus (Fig. 1(a)) was a mini-mold with $120 \mathrm{~mm}$ width (w2) for the mould, $40 \mathrm{~mm}$ wide (w1) as (a long constrained direction, CD), $250 \mathrm{~mm}$ long (along flow direction, FD) and $50 \mathrm{~mm}$ deep (along loading direction, LD), allowing samples up to $40 \mathrm{~mm}$ high (i.e. dimension along LD) to be compressed with that mini-mold. The difference between the two deeps (d1-d2) is equal to the thickness of the sheet, where, the extensions of the material along flow direction and constrain direction show the length and the wide of the sheet. This apparatus allows the sample to flow only along the flow direction (FD). The second apparatus (Fig. 1(b)) was a set of a square mould with 120 width and length. This apparatus enhances the sample to flow in two directions (FD1 and FD2). The third apparatus (Fig. 1(c)) was similar to the first apparatus (Fig. 1(a)) but small in size, weight and dimensions. The fourth apparatus (Fig. 1(d)) was similar to the first apparatus (Fig. 1(b)) but small in size, weight and dimensions.

$<$ Figure 1>

The advantage of a deep mould is that the samples produced by compression in such a mould are relatively large, so that the structure and orientation produced by plastic deformation and the macroscopic recovery behavior could be studied easily. Due to a large lateral surface area of the sample, friction forces between the sample and mould could not be neglected, which resulted in overestimation of the stress. That was the case when the sample placed on the mould was accurately weighted prior to compression. The size of specimens used in apparatus (Fig. 1(a)) was $3.9 \times 50 \times 35 \mathrm{~mm}^{3}$ (along CD, FD and LD, respectively), while the square apparatus (Fig. 1(b)) was 5x $6 \times 4 \mathrm{~mm} 3$, the apparatus (Fig. 1(c)) was $12.5 \times 5 \times 17 \mathrm{~mm}^{3}$ (CD, FD, and LD, respectively), and the apparatus (Fig. 1(d)) was $4 \times 3 \times 3 \mathrm{~mm}^{3}$. All PIF experiments were performed as shown in Fig.2 at a constant load and at room temperature for 1 to 25 days. The residual paraffin oil was extracted by N-hexane at room temperature for 1 hour repeated many times until extraction reached equilibrium state.

$<$ Figure 2>

\section{Characterizations}

\subsection{Calorimetric measurements}

The differential scanning calorimetry DSC measurements were carried out using a Perkin-Elmer Diamond DSC Differential Scanning Calorimeter controlled by a Thermal Analyst 2000 system. Typical sample weights used were approximately $4 \mathrm{mg}$ and were placed in sealed Aluminum pans. The heating/cooling rate of $10^{\circ} \mathrm{C} / \mathrm{min}$ was applied and upper temperature ranges of $40-190^{\circ} \mathrm{C}$ were selected. Prior to use, the calorimeter was calibrated with Indium standard $\left(\mathrm{Mp} 156.5^{\circ} \mathrm{C}\right)$. An empty Aluminum pan was used as a reference. The specimens were tested in Nitrogen as an inert gas with flow rate $20.0 \mathrm{mil} / \mathrm{min}$.

\subsection{Transmission Electron Microscopy (TEM)}

The transmission electron microscopy of the UHMWPE/MMT gel sheets observations were conducted on a Hitachi $\mathrm{H}-800$ (Japan) operated at an accelerating voltage of $200 \mathrm{KV}$. Ultra-thin sections $(60-80 \mathrm{~nm}$ in thickness) were obtained at room temperature cryogenic environment using a Reichert-Jung Ultracut E microtome with a diamond knife. The Samples for TEM analysis were cut parallel to the LD-FD plane, as depicted in Fig.1. The thin sections were then put on the 100-mesh Formvar/carbon coated copper grids for TEM observation.

\subsection{Scanning electron microscopy (SEM)}

The scanning electron microscopy (SEM) cryogenically fractured surfaces of the UHMWPE/OMMT gel sheets were observed by S-3000N type scanning electron microscopy Hitachi, Japan. The SEM samples were gold sputtered prior to observation.

\section{Results and Discussion}

\subsection{X-Ray Diffraction}

Polymer/clay nanocomposites are formed by the insertion of polymer chains between the clay layers. Practically, 
it is difficult to define nanocomposite structures by a single measurement. The most common method to obtain structural information is X-ray diffraction (XRD). XRD can be used to measure the interlayer spacing distance (d) between clay layers.

The WXRD patterns of samples are given in Fig. 3. The diffraction patterns of UHMWPE/MMT with different MMT contents are the same.

Insert Figure 3 about here

To study their crystal structure, peak-fit analyzing software was used to obtain a series of crystal parameters, namely, interplanar space (d), half-width (b), apparent crystal size ( $\left.L_{h k l}\right)$ to mention a few. The degree of crystallinity $\left(\mathrm{X}_{\mathrm{c}}\right)$ are given by the equation as follows:

$$
X_{c}=1-\frac{A_{a}}{A_{c}+A_{a}}
$$

Where $A_{a}$ and $A_{c}$ are the areas of the amorphous and the total crystal peaks.

The interplanar spacing (d) and apparent crystal size $\left(\mathrm{L}_{\mathrm{hkl}}\right)$ values for the different peaks can be calculated by Bragg's law and Scherrer's formula (1969), respectively.

$$
\begin{aligned}
& d=\frac{\lambda}{2 \sin \theta} \\
& L_{h k l}=\frac{k^{\prime} \times \lambda}{\beta_{o} \times \cos \theta} \\
& \beta_{o}=\sqrt{\beta^{2}-b_{o}^{2}}
\end{aligned}
$$

$<$ Table 2>

Table 2 shows that most XRD results of the MMT in UHMWPE/MMT have been partially exfoliated in the nanocomposites. As the content of Org-MMT increases, there are also some intercalated structures lying in the composites, which are caused by the weak peaks appearing on the XRD pattern. The partially exfoliated and intercalated of the MMT clay indicate that the MMT was dispersed inside the UHMWPE/MMT nanocomposite.

\subsection{DSC results}

The degree of crystallinity (Xc) was calculated using the following equation:

$$
\mathrm{X}_{\mathrm{c}}=\frac{\mathrm{H}_{\mathrm{mc}}}{\mathrm{H}} \times 100 \%
$$

Where: $\mathrm{X}_{\mathrm{c}}$ is the degree of crystallinity $\%$

$\mathrm{H}_{\mathrm{mc}}$ is the melting enthalpy of crystallization of $\operatorname{HDPE}(\mathrm{J} / \mathrm{g})$

$\mathrm{H} \circ$ is the standard melting enthalpy of crystallization of $\operatorname{HDPE}(\mathrm{J} / \mathrm{g})$

In practice, the heat of fusion of pure crystalline polyethylene is taken to be in the range of 276.15- $292.88 \mathrm{~J} / \mathrm{g}$, with a commonly accepted value of $288.70 \mathrm{~J} / \mathrm{g}$ Flory (1963). The degree of crystallinity and the peak melting temperature determined from DSC for the first run are summarized in Table 3, Figs. 4 and Figs. 5. The degree of crystallinity decreased slightly for the UHMWPE gel sheet with the increase of MMT clay percent. A small variation is observed for the melting temperature of the samples. The difference in the degree of crystallinity estimated from DSC reflects the differential result of MMT clay content on the crystalline phase, interface, and amorphous phase. Table 3 presents the crystalline percent for UHMWPE $4 \%-5 \%$ and MMT clay $0 \%, 10 \%$ and $20 \%$.The increase of MMT clay content resulted in a $10.3 \%, 18.7 \%$, and $27.2 \%$ decrease in the crystalline for UHMWPE $4 \%$ and $14.5 \%, 13.1 \%$, and $25.9 \%$ for UHMWPE $5 \%$ where the increase of UHMWPE from $4 \%$ $5 \%$ and $0 \%, 10 \%$, and $20 \%$ MMT clay resulted in a $9.3 \%, 4.9 \%$, and $10.9 \%$ increase in the crystalline respectively.

Insert Table 3, Figure 4 and Figure 5 about here

Fig. 4 and Fig. 5 present the DSC melting thermograms of pure UHMWPE 4\%, 5\%, and UHMWPE 4\%, 5\% with 
$10 \%, 20 \%$ MMT clay, processed in the same conditions. The thermograms of the UHMWPE $4 \%$ and $5 \%$ specimen show the melting peak $\left(\mathrm{T}_{\mathrm{m}}\right)$ at $133.6^{\circ} \mathrm{C}$ and $131.8^{\circ} \mathrm{C}$ respectively. The temperature of the melting of the component in blends increased slightly compared to the pure UHMWPE. The above changes demonstrate that the presence of MMT clay in the nanocomposite markedly influences the crystallization and the thermal behavior of the UHMWPE component.

\subsection{TEM results}

TEM results for the UHMWPE/MMT clay nanocomposite sheets are shown in Fig.7 and Fig.8. They provide some direct evidence of MMT clay nanoparticles dispersion in the nanocomposite. The exfoliated and intercalated MMT clay nanoparticles are almost parallel to one another and they are highly aligned along the flow direction and parallel to the part surface as in shown in Fig.6. Some MMT clay nanoparticles started to deviate from being aligned with the flow direction as depicted in Fig.7. The difference in the degree of planar orientation between the surface and the inner layers becomes more noticeable. It is clear that the MMT clay nanoparticles were less aligned orderly along the flow direction in the nanocomposite. This is may be due to the effect of the quench of paraffin oil and extension during PIF and extraction stages.

$<$ Figure 6 and Figure $7>$

The TEM images (Fig. 7) of UHMWPE/MMTclay nanocomposite sheets confirmed the presence of the exfoliated structure and the good dispersion of the MMT clay nanoparticles in the nanocomposite. The TEM image of UHMWPE/MMT clay (Fig.8) confirmed the SEM results in term of showing a significant degree of intercalation between the silicate layers in the nanocomposite. Similar results have been obtained by (Filippi et al, 2007; Ali et al, 2007; Asim et al, 2005; Quang et al, 2007; Fang et al, 2007; Periyayya et al, 2005) when using MMT clay to prepare nanocomposite utilizing different materials and processes. At a higher content of MMT clay nanoparticles, a complete and effective entry of monomers into the organically modified silicate layers is very difficult Theng (1979). The TEM can present more direct information on morphology in real space. All the TEM images for the both contents of MMT clay nanoparticles show an intercalated structure.

$<$ Figure $8>$

\subsection{Scanning Electron Microscopy (SEM) results}

Figs $(9,10$, and 11) present SEM micrographs of the fracture surface of UHMWPE/MMT clay nanocomposites processed using gel and PIF processes, respectively, for MMT clay content of $10 \%$ and $20 \%$ and UHMWPE content of $4 \%$ and $5 \%$. The differences in scattering densities of MMT clay and UHMWPE facilitate differentiation of MMT clay aggregates, their characteristics and distribution. These micrographs provide important insights concerning MMT clay distribution, intercalation, and exfoliation, and help in better understanding the processing-structure property relationships. The fracture surfaces of pure UHMWPE specimens Fig.9 $(\mathrm{a}, \mathrm{b})$ revealed that the UHMWPE chains were high fully aligned along the flow direction, and a river-line markings, which can affect the crystallinity of the UHMWPE gel nanocomposite sheet.

$<$ Figure 9>

Fig.10 shows the micrographs of the fracture surface of UHMWPE/MMT clay nanocomposites for MMT clay content of $10 \%$ and UHMWPE content of $4 \%$ and $5 \%$, which highlight that the UHMWPE/MMT clay nanocomposite sheets were intercalated, exfoliated and the MMT clay nanoparticles was dispersed as in Fig.6. Also many voids were observed due to the removal of paraffin oil during the PIF and extraction processes.

$<$ Figure 10>

Fig.11 shows the micrographs of the fracture surface of UHMWPE/MMT clay nanocomposites for MMT clay content of $20 \%$ and UHMWPE content of $4 \%$ and $5 \%$, which exhibited a gel-like layer, and many voids between these layers. Fig.11 confirms that the increase of MMT clay content revealed a structure having large clay aggregates, which perform as stress concentrators hence, increases the amount of the oriented lamellar in the SEM images, decreases the degree of crystallinity and increases the melting temperature in the DSC images. In contrast, the samples containing 20\% MMT clay permitted the intercalation, exfoliation and dispersion of MMT clay.

Insert Figure 11 about here

\section{Conclusion}

This study provided evidence that a significant and challenging task in understanding the advantages of the addition of MMT nanoclay into UHMWPE lies in ensuring the uniform dispersion of the high aspect ratio crystal-like platelets in the UHMWPE/MMT clay nanocomposites. XRD and TEM indicate that the MMT 
dispersed randomly, intercalated and exfoliated partially UHMWPE/MMT clay nanocomposites were successfully achieved using two methods gel and PIF processes. The rheological properties of UHMWPE/MMT clay nanocomposites were affected by the content and the degree of dispersion of the MMT clay nanoparticles. With the increase of MMT clay nanoparticles content, fully dispersed UHMWPE/MMT clay nanocomposites with good nanoscale intercalation of clay platelets showed remarkable improvements in rheological over their unfilled base material at very small levels of clay (10-20 wt \%), when compared with those containing mixtures of aggregated and intercalated clay. The addition of MMT clay nanoparticles decreased the melting temperature and crystallization degree of the UHMWPE/MMT clay nanocomposites.

\section{Acknowledgements}

The research is financed by National Natural Science Foundation of China (Grant No. 50833002).

\section{References}

Alexander L. E. (1969). X-ray diffraction methods in polymer science, Wiley, New York

Alexandre M., Dubois P. (2000). Polylayered silicate nanocomposite preparation, properties and uses of a new class of materials. Mater. Sci. \& Eng., 28: 1-63.

Ali D., Maybelle W., Ahmet K., Christopher W. M., Michael T. (2007). Intercalated (LLDPE)/clay nanocomposites prepared with oxidized polyethylene as a new type compatibilizer: Structural, mechanical and barrier properties. European Polymer Journal, 43, 3737-3749.

Asim P., Sadhan C. Jana. (2005). Synthesis of thermoplastic PE nanocomposites of reactive nanoclay by bulk polymerization methods. Polymer, 46, 3275-3288.

Bartczak Z., Krasnikova N. P., \& Caleski A. (1996). Morphology and texture of HDPE/PS blends deformed by plane strain compression. J. of Appl. Polymer Science, 62, 167-179.

Bartczak Z., \&Lezak E. (2005). Evolution of lamellar orientation and crystalline texture of various polyethylenes and ethylene-based copolymers in plane-strain compression. Polymer, 46, 6050-6063

Fang Z. P., Xu Y. Z., Tong L. F. (2007). Effect of clay on the morphology of binary blends of Polyamide 6 with HDPE and HDPE graft Acrylic Acid. Polym. Eng.and Sci., 551-559.

Federica B., Andrea T., Andreas L., Doris P., Alberto F., Giuliano T.,\& Giovanni C. (2008). Intercalation degree in PP/organoclay nanocomposites role of surfactant structure. Polymers for Advanced Technologies, 19, $547-555$.

Filippi S., Elena M., Cristina M., \& Pierluigi M. (2007). Comparison of solution blending and melt-intercalation for the preparation of poly(ethylene-co-acrylic acid)/organoclay nanocomposites. European polymer Journal, 43, $1645-1659$.

Flory P.J., Vrij A. (1963). Melting points of Linear-chain homologs: The normal paraffin hydrocarbons. Journal of American Chemical Society, 85, 3548.

Ganter M., Gronski W., Riechert P., \& Mulhaupt R. (2001). Rubber nanocomposites: Morphology and mechanical properties of BR and SBR vulcanizates reinforced by organophilic layered silicates. Rubber Chemistry and Technology, 74, (2), 221-235.

Gonzalez L., J. A., M. H. Acar, S. W. Ryu, Ruzette A. V. G., Mayes A. M. (2003). Low temperature processing of baroplastics by pressure induced flow. Nature, 426, 424 - 428.

Homminga D., Goderis B., Hoffman S., Reynaers H., \& Groeninckx G. (2005). Influence of shear flow on the preparation of polymer layered silicate nanocomposites. Polymer, 46, 9941.

Hotta, S., \& Paul, D. R. (2004). Nanocomposites formed from linear low density polyethylene and organoclays. Polymer, 45, 7639-7654.

Knudson M. L., Powell C. (2002). P. C. T. Int. Pat. WO: 02/070589 A2.

Min K.D., Kim M.Y., Choi K. Y., Lee J. H. \& Lee S. G. (2006). Maleated and non-maleated PE-MMT layered silicate blown films: creep, dispersion and crystallinity. Polymer Bulletin, 57, 101-108.

Mousa A., Kocsis J.K. (2001). Rheological \& thermodynamical behavior of Styrene/Butadiene Rubber Organoclay Nanocomposites. Macromolecular Material and Engineering, 286, (4): 260-266.

Osman M.A., Jörg E.P. R. (2005). Interfacial interactions and properties of PE layered silicate nanocomposites. Macromolecular Rapid Communications, 26, 880-884. 
Periyayya U., Yoon B. H., Kee S. N., \& Youn S. L. (2005). Exfoliated high- impact PS/MMT nanocomposites prepared using anchored cationic radical initiator MMT hybrid. European Polymer Journal, 41: 1582-1588.

Quang T. N., \& Donald G. B. (2007). An improved technique for exfoliating and dispersing nanoclay particles into polymer matrices using supercritical carbon dioxide. Polymer, 48, 6923-6933.

Sarashi H. (2003). Japan Patent No. JP: 2003327751.

Sadhu S., \& Bhowmick A. K. (2004). Preparation and properties of nanocomposites based on Acrylonitrile-Butadiene Rubber, Styrene-Butadiene Rubber, and Polybutadiene Rubber. Journal of Polymer Science Part B: Polymer Physics, 42, 1573- 1585.

Tanniru M., Yuan Q. \& Misra R.D.K. (2006). On significant retention of impact strength in clay reinforced (HDPE) nanocomposites. Polymer, 47, 2133-2146.

Theng B. K. G. (1979). Formation and Properties of Clay Polymer Complexes. New York: Elsevier,

Yang J. X., Tom H., Wang W. X., Jun L., Brown P., Martyn P., Lesterb E.,\& Steven M. H. (2008). Preparation of hybrid polymer nanocomposite microparticles by a nanoparticle stabilized dispersion polymerization. Journal of Materials Chemistry, 18: 998-1001.

Yong L., Wu Q. L., Craig M. C., Fei Y., Xu Y. J. (2007). Influence of nanoclay on properties of HDPE/Wood Composites. Journal of Applied Polymer and Science, 106: 3958-3966.

Zhao C. G., Qin H. L., Gong F. L., Meng F., Zhang S. M., Yang M. S. (2005). Mechanical, thermal and flammability properties of polyethylene/clay Nanocomposites. Polymer Degradation and Stability, 87: 183-189.

Table 1. Materials used in this study

\begin{tabular}{ccccc}
\hline $\begin{array}{c}\text { Material } \\
\text { Samples }\end{array}$ & $\begin{array}{c}\text { UHMWPE } \\
\mathrm{wt} \%\end{array}$ & $\begin{array}{c}\text { MMT Clay wt } \% \text { out of } \\
\text { UHMWPE wt } \%\end{array}$ & $\begin{array}{c}\text { Paraffin Oil } \\
\mathrm{wt} \%\end{array}$ & $\begin{array}{c}\text { Anti Oxidant } \\
\mathrm{wt} \%\end{array}$ \\
\hline 1 & 4 & 0 & 95.55 & 0.45 \\
2 & 4 & 10 & 95.025 & 0.4775 \\
3 & 4 & 20 & 95.525 & 0.4725 \\
4 & 5 & 0 & 94.50 & 0.45 \\
5 & 5 & 10 & 94.0275 & 0.4725 \\
6 & 5 & 20 & 93.53 & 0.47 \\
\hline
\end{tabular}

Table 2. XRD results of UHMWPE and its nanocomposite samples

\begin{tabular}{ccccc}
\hline Sample & $2 \theta$ & d-spacing $(\mathrm{nm})$ & difference & Crystanillity $\%$ \\
\hline OMMT & 19.72 & 3.01 & - & - \\
4 Pure $\%$ & 19.20 & 4.17 & 1.16 & 52.34 \\
5 Pure\% & 19.22 & 4.21 & 1.20 & 55.73 \\
$4 / 10 \%$ & 19.19 & 4.54 & 1.53 & 54.43 \\
$5 / 10 \%$ & 19.36 & 4.52 & 1.51 & 58.52 \\
$4 / 20 \%$ & 19.34 & 4.60 & 1.59 & 56.35 \\
$5 / 20 \%$ & 19.34 & 4.62 & 1.61 & 58.70 \\
\hline
\end{tabular}


Table 3. DSC crystallinity and melting temperature of UHMWPE and its nanocomposite samples

\begin{tabular}{ccccccc}
\hline Samples & \multicolumn{3}{c}{$4 \%$} & \multicolumn{5}{c}{$5 \%$} \\
\hline MMT clay \% & 0 & 10 & 20 & 0 & 10 & 20 \\
Crystallinity \% & 65.8 & 64.4 & 52.3 & 69.2 & 67.7 & 58.7 \\
Melting temperature & 124.692 & 133.608 & 126.323 & 121.55 & 131.788 & 130.844 \\
\hline
\end{tabular}
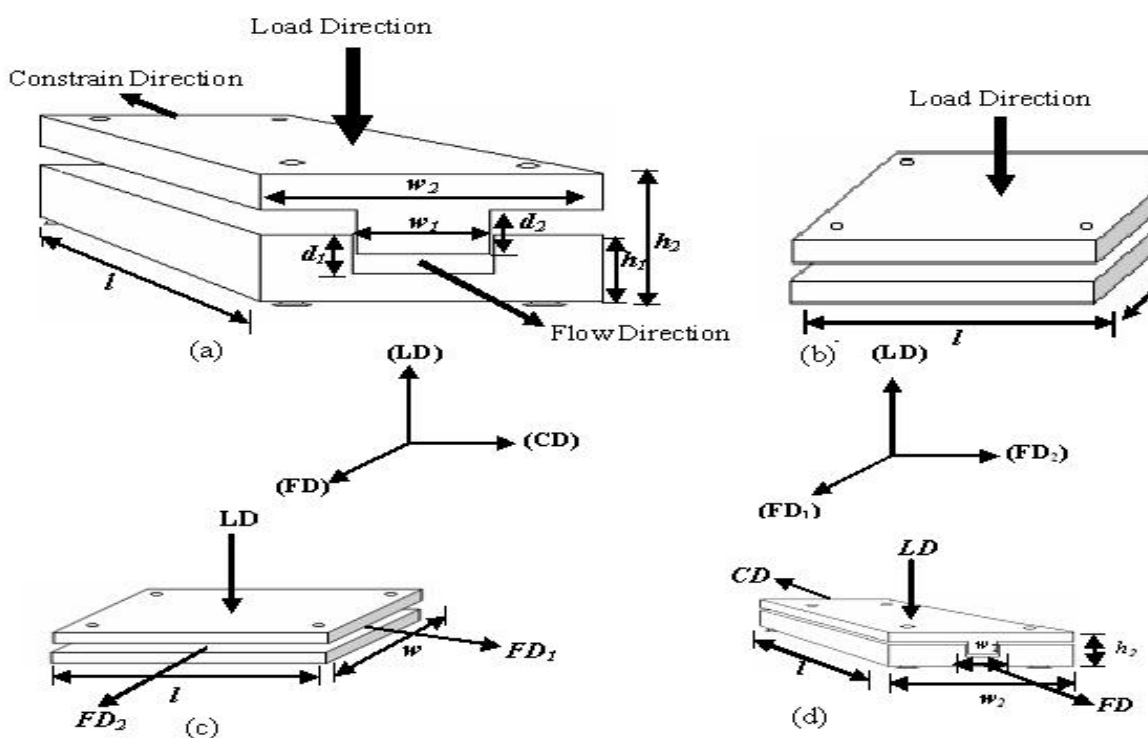

Figure 1. Illustration of the types of a mini-mold apparatus

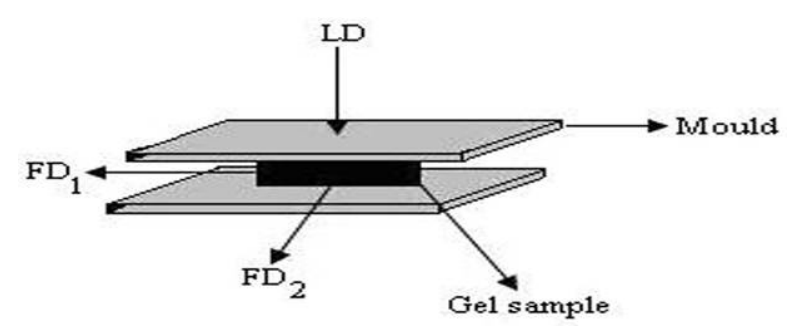

Figure 2. The PIF process of the UHMWPE gel sheet 


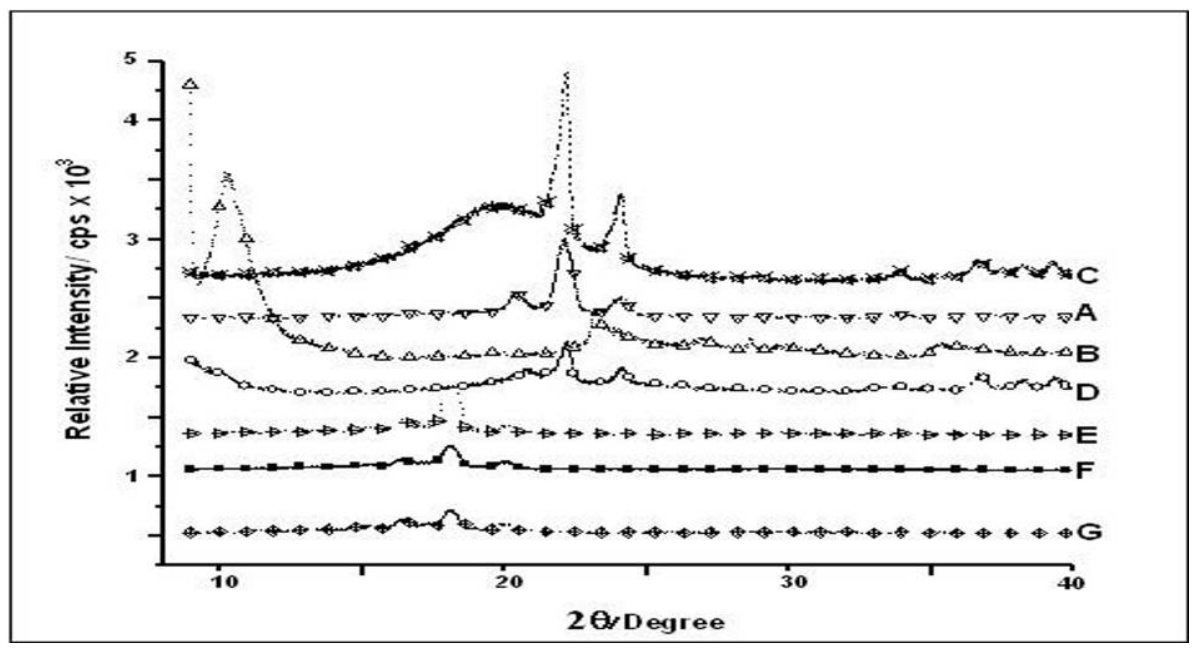

Figure 3. The XRD patterns of UHMWPE and its nanocomposite samples: (A) OMMT (B) 4\% Pure (C) 5\% Pure (D) $4 / 10 \%$ (E) $5 / 10 \%$ (F) $4 / 20 \%$ and (G) $5 / 20 \%$

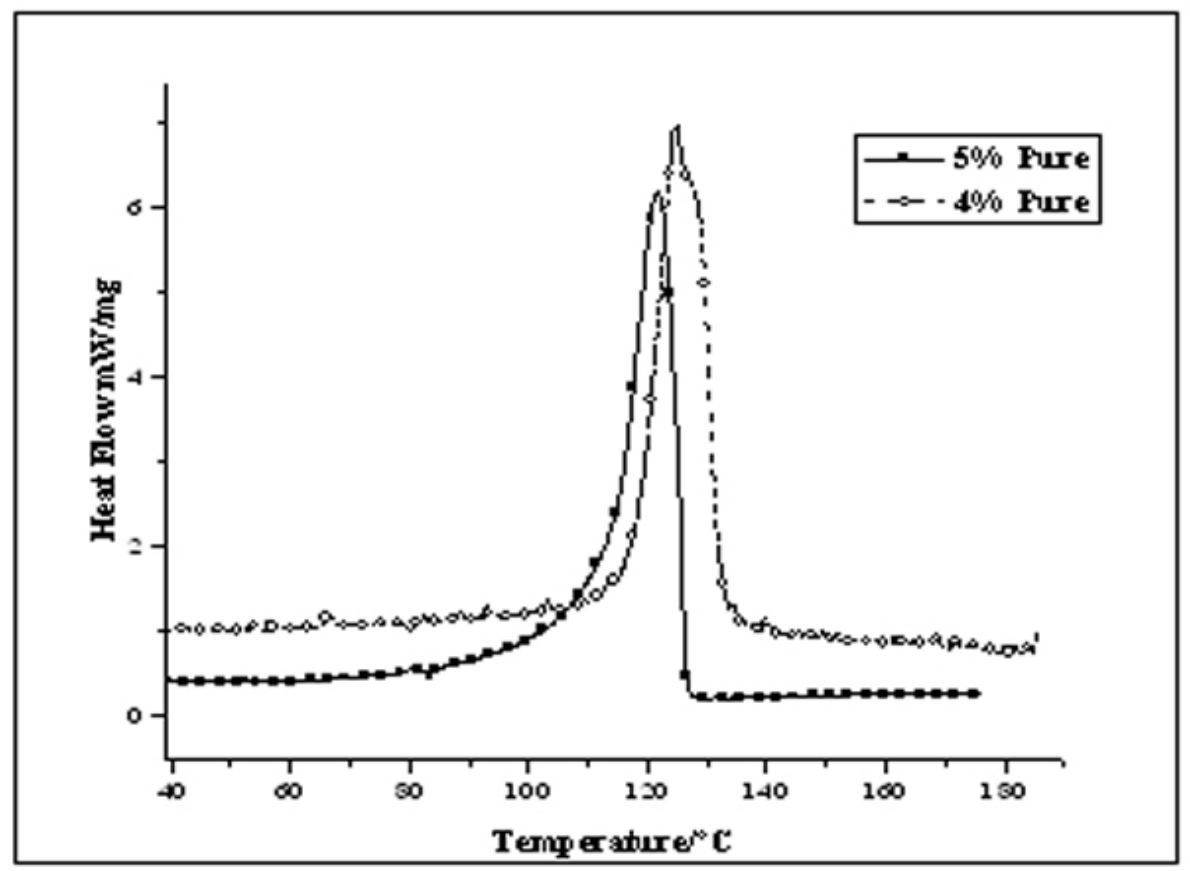

Figure 4 . The DSC of $4 \%$ and $5 \%$ UHMWPE pure 


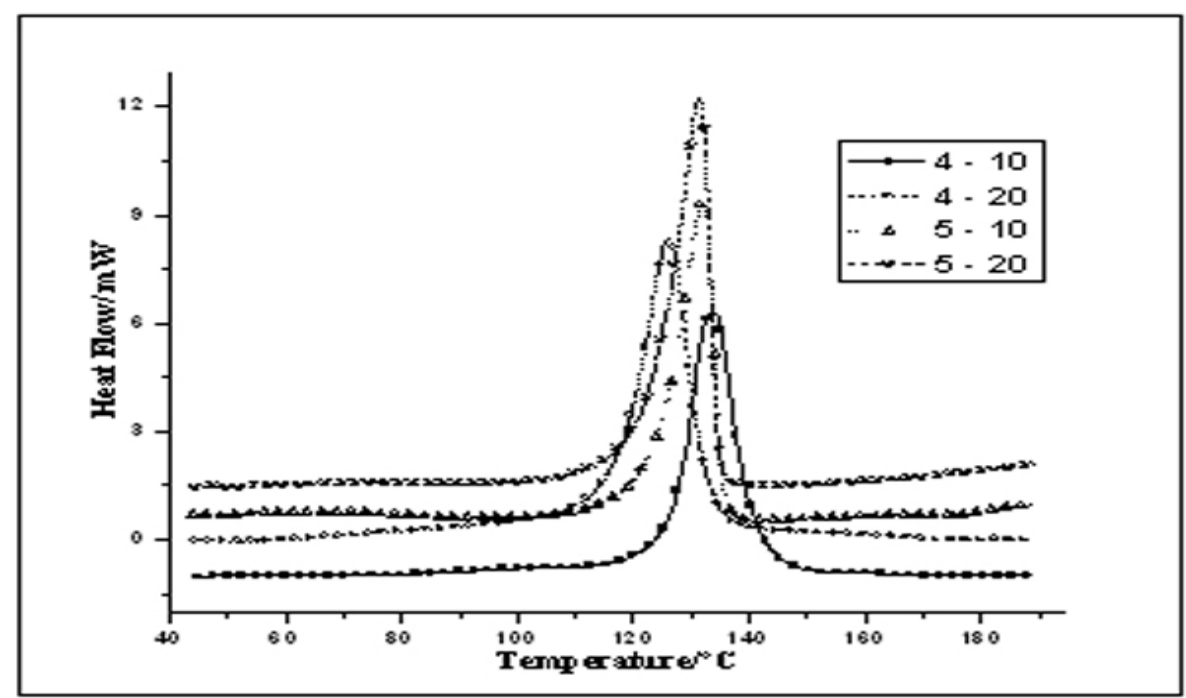

Figure 5. The DSC of $4 \%$ and 5\% UHMWPE with $10 \%$ and $20 \%$ MMT clay

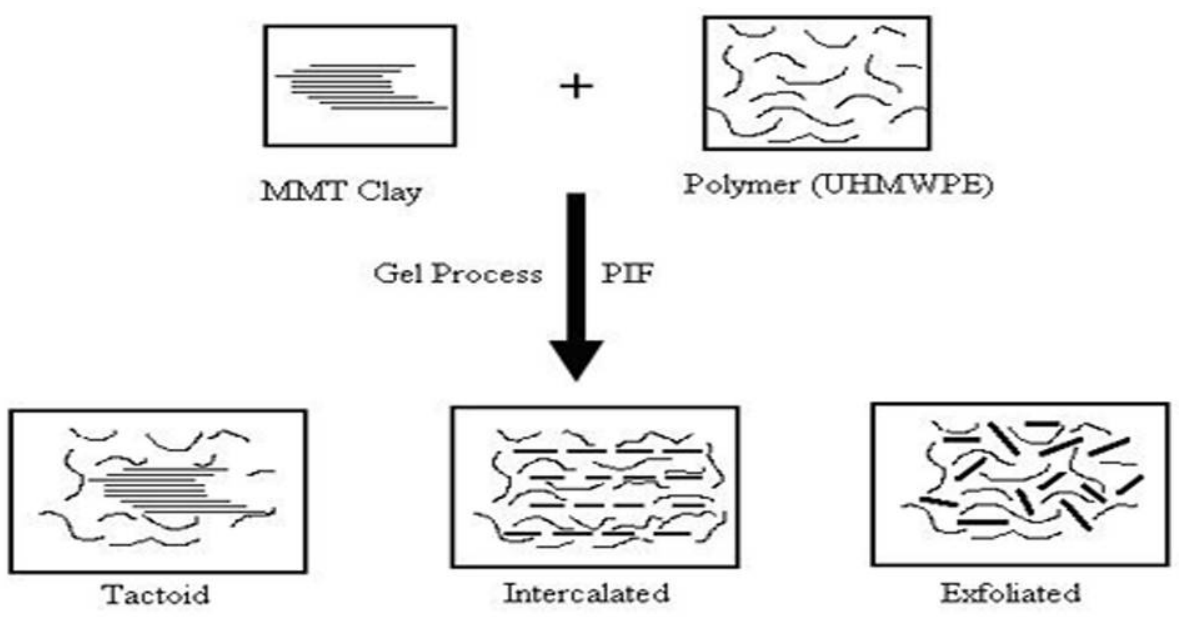

Figure 6. Schematic illustration of Intercalation and Exfoliation of UHMWPE nanocomposite
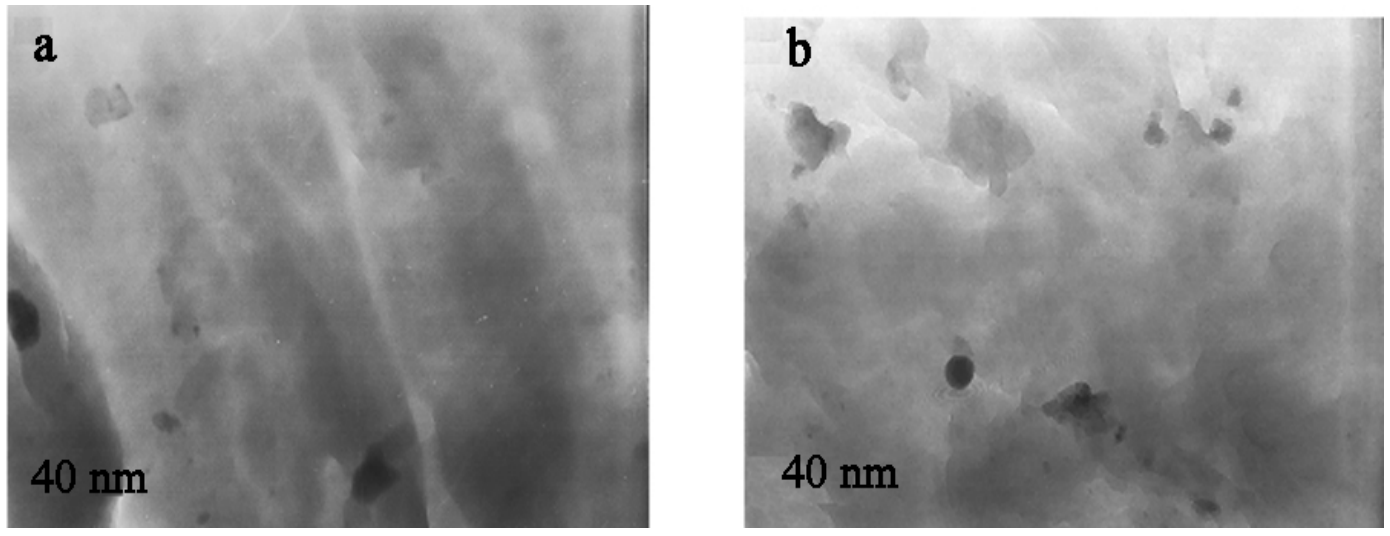

Figure 7. TEM micrographs of UHMWPE /montmorillonite clay nanocomposite with contents of $10 \%$ MMT clay and (a) (UHMWPE 4/10 \%), (b) (UHMWPE 5/10\%) 

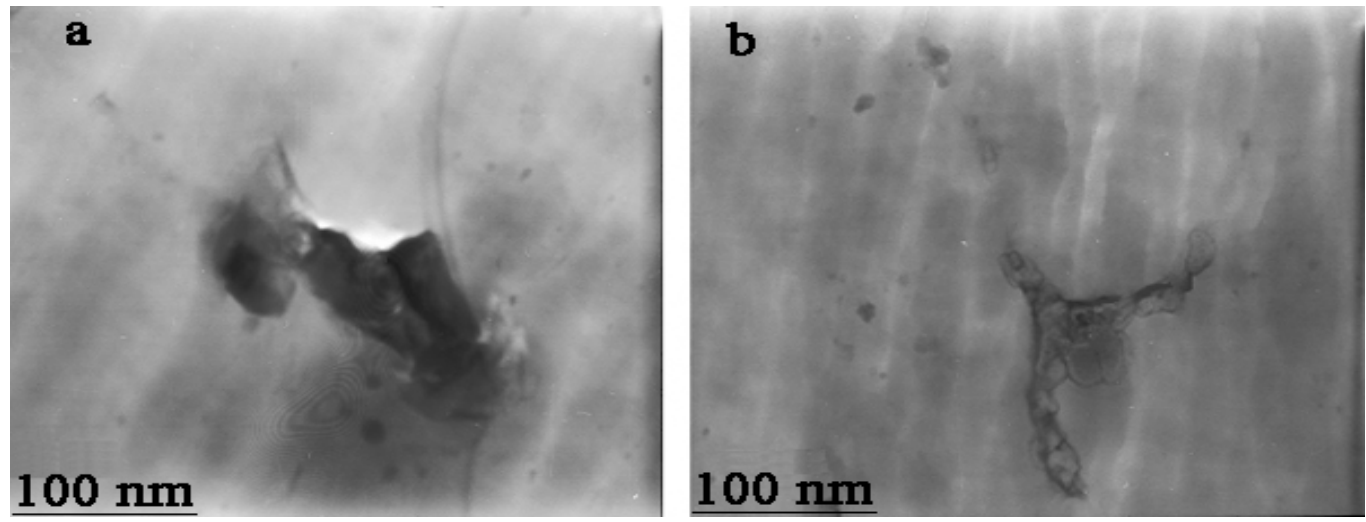

Figure 8. TEM micrographs of UHMWPE /MMT clay nanocomposite with contents of $20 \%$ MMT clay and (a) (UHMWPE 4/20 \%), (b) (UHMWPE 5/20\%)

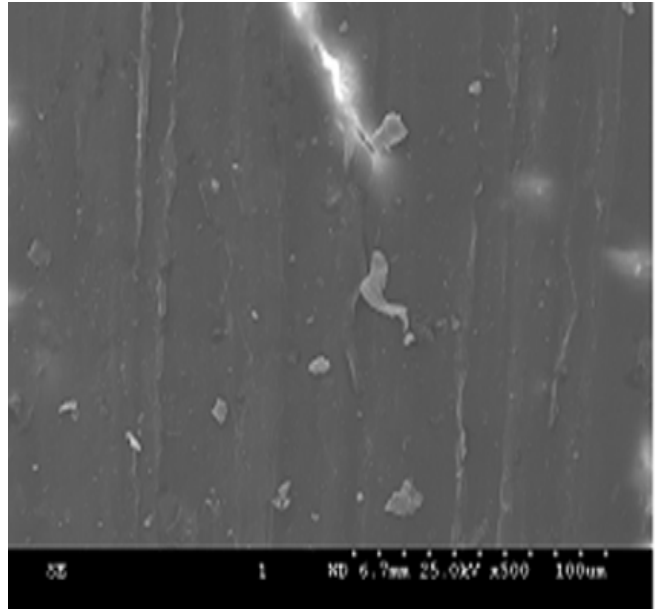

(a)

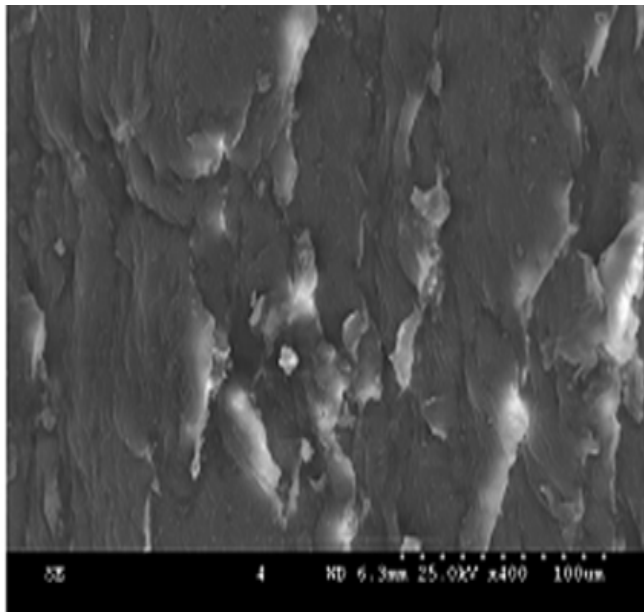

(b)

Figure 9. SEM micrographs of fracture surface of pure UHMWPE nanocomposite fabricated by gel and PIF processes (a) 4\% pure UHMWPE, (b) 5\% pure UHMWPE volume fractions

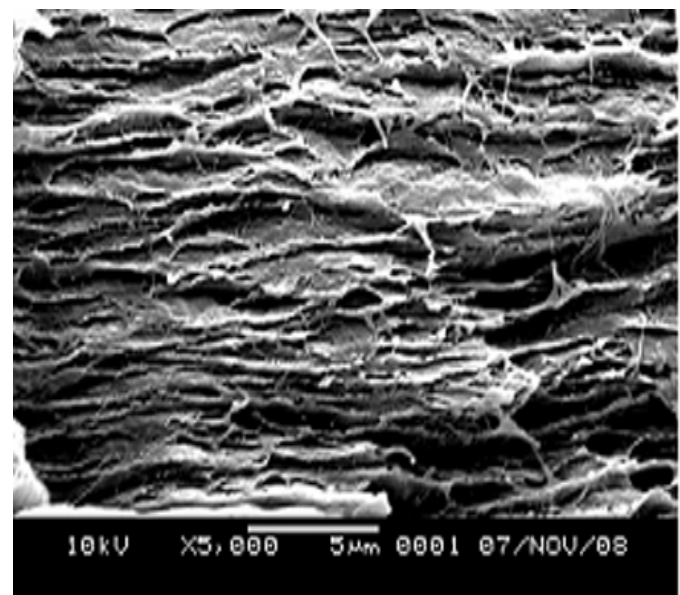

(a)

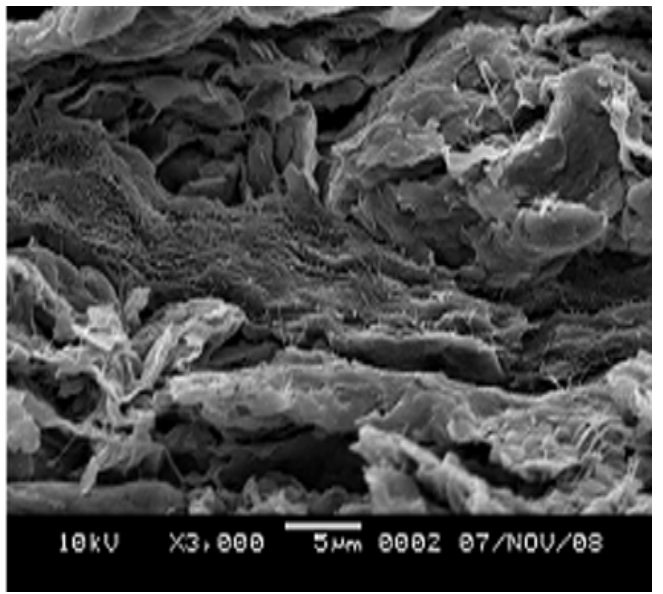

(b)

Figure 10. SEM micrographs of fracture surface of UHMWPE/MMT clay nanocomposite: (a) 4\% UHMWPE and 10\% MMT clay volume fraction, and (b) 5\% UHMWPE and 10\% MMT clay volume fraction volume fractions 


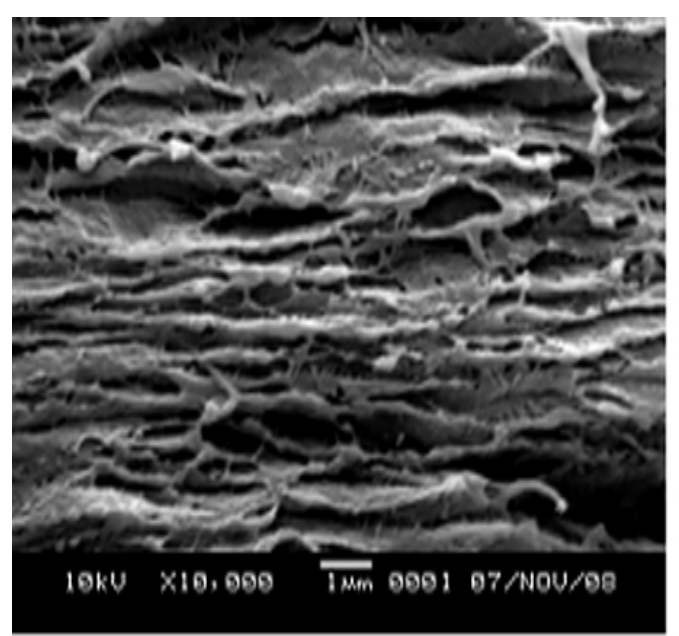

(a)

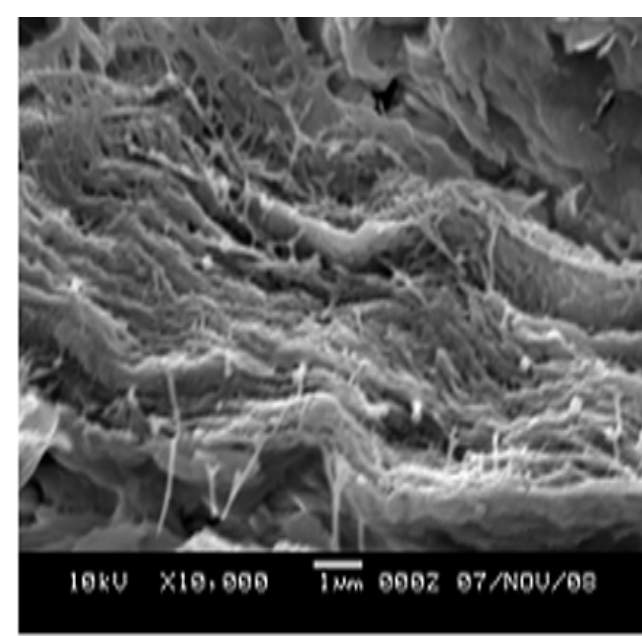

(b)

Figure 11. SEM micrographs of fracture surface of UHMWPE/MMT clay nanocomposite (a) 4\% UHMWPE and $20 \%$ MMT clay volume fraction, and (b) 5\% UHMWPE and 20\% MMT clay volume fraction volume fractions 